\title{
Effect of Housing Systems - Barn vs Cage on the First Phase Egg Production and Egg Quality Traits of Laying Pullet
}

\author{
Musabbir Ahammed and Sang Jip $\mathrm{Ohh}^{\dagger}$ \\ College of Animal Life Science, Kangwon National University, Chuncheon 200-701, Rep. of Korea
}

\begin{abstract}
With an increasing concern on laying hen welfare, barn system has appeared as one of the alternatives to replace the conventional cage. This study was conducted to compare the early laying performance and egg quality at the barn system with those at the conventional cage. A total of 288 shaver-579 brown layers were used for 9 weeks $\left(21^{\text {st }}\right.$ to $30^{\text {th }}$ weeks of age) feeding study. Feed consumption and egg weight were significantly $(P<0.01)$ higher at barn than at cage. However, there were no significant differences between two housing systems on hen day egg production (HDEP), egg mass, body weight, feed efficiency and livability. In case of egg quality parameters, shell thickness, albumen height and Haugh unit were significantly $(P<0.05)$ different between two systems. Haugh unit and albumen height were significantly higher in eggs produced at cage $(88.97$ and $8.16 \mathrm{~mm})$ compared than those produced at barn $(83.11$ and $6.87 \mathrm{~mm})$, whereas shell thickness was thicker in eggs produced at barn than those produced at cage. Shape index, breaking strength, blood spots and yolk index data were not influenced significantly by the types of housing system. To implement welfare bestowing production, this study showed that the barn system can replace the conventional cage without serious sacrifices on starting phase egg production. In addition, this study suggested that the barn system need to be optimized in view of daily feed consumption.
\end{abstract}

(Key words : laying pullets, housing system, productive performance, egg quality)

\section{INTRODUCTION}

Conventional cage has been a worldwide popular housing system for rearing modern laying hens. Keeping layers in conventional cages was known to have advantages on reducing labor requirement and improving hygiene. With the emerging trends on animal welfare concern, however, the conventional cage has been forced to be replaced by other alternative systems. Although barn system has appeared as an alternative system, replacement of the housing system cannot be an easy task since that might cause changes in production performance. It has been well witnessed that the type of housing system imparts considerable effects on performance and production traits such as egg weight, feed efficiency, daily feed consumption and mortality (Taylor and Hurnik, 1996; Suto et al., 1997). Recently, the housing system has evaluated in views of quality and impact on animal welfare and behavior. Since the barn system was able to provide an opportunity for hens to explore litter materials, it has lowered the risk of feather pecking and cannibalism. Although the air qual- ity is primarily influenced by the management of farm and system, the barn system is known to emit relatively higher ammonia than cage system (Groot Koerkmp, 1998), which would hurt quality of welfare.

It is therefore needed to compare many parameters between two housing systems. Due to the relatively short history on laying hen welfare, there have been only limited studies available for this comparison. Al-Awadi et al. (1995) reported that cage hens exerted better egg production and feed efficiency compared with barn hens when the hens reared under moderate weather condition, but that the performance was reversed when the hens exposed to hot stressful weather condition. This result implied that the benefit of the barn system could be prominent under extreme weather condition.

It is well known that egg quality primarily depends on genetic background but also on housing system and management of birds (Fraser and Bain, 1994; Vits et al., 2005). However, there is little information about the effect of housing system on egg quality.

Therefore, the objective of the present study was to com-

\footnotetext{
${ }^{\dagger}$ To whom correspondence should be addressed : sjohh@kangwon.ac.kr
} 
pare both production performance and egg quality of laying pullets that were reared either at barn or at conventional cage.

\section{MATERIALS AND METHODS}

\section{Experimental Housing Systems}

Both barn and cage systems were allocated to the same shed type open sided house and divided into two rooms. Both rooms were 7.2 meter long, 6.4 meter wide and 3.0 meter in height. One room was used for barn and divided into three separated pens of equal size. Dry sand of $10 \mathrm{~cm}$ depth was spread on floor as litter. One community type wooden nest box was provided in each replication of the barn having five small nests. Stocking density for pullets maintained on barn was $0.32 \mathrm{~m}^{2} /$ bird. In another room, three-tier individual battery cage were used for cage system. Two pullets were housed in each unit of cages with $0.75 \mathrm{~m}^{2}$ of floor area per bird.

\section{Experimental Birds and Diets}

A total of 288 brown laying pullets (Shaver 579) were used for the experiment. All the pullets were reared up to $17^{\text {th }}$ week of age in the barn under the same environmental and feeding conditions. At $17^{\text {th }}$ week, birds were allocated randomly to the experimental groups having three replications in each group. The number of birds in each replication was 48. Although some pullets started to lay between 18 to 20 weeks, the experimental data were collected from $21^{\text {st }}$ week to $30^{\text {th }}$ week.

In both housing systems, all birds were fed manually and water was provided through nipple drinkers. From $20^{\text {th }}$ week of age, all birds received a diet containing $17.4 \% \mathrm{CP}, 2,808$ $\mathrm{ME} \mathrm{kcal} / \mathrm{kg}$ and $3.47 \% \mathrm{Ca}$. Nutrient content of the diet (Table 1) was prepared to meet the recommendation of Shaver-579 Layer Management Guide 2009. Mash feed were provided three times a day to meet there commendation guide.

The 16L:8D lighting program was implemented throughout the study. Temperature and relative humidity $(\mathrm{RH})$ were between 24 and $27^{\circ} \mathrm{C}$ and $75 \%$, respectively. All birds were vaccinated according to the recommended program. The experimental birds were debeaked in the early age of life.
Table 1. Ingredients and chemical composition of experimental diet

\begin{tabular}{lc}
\hline \multicolumn{1}{c}{ Ingredients } & Basal diet \\
\hline Formula (\%) & \\
Maize & 53.00 \\
Soybean meal & 11.00 \\
Rice polishing & 15.00 \\
Sesame oil cake (32\%) & 11.00 \\
Protein contrite (50\%) & 3.00 \\
Bone meal & 1.00 \\
Oyster shell & 5.00 \\
Salt & 0.40 \\
*Vitamin-mineral premix & 0.20 \\
Choline-Cl (60\%) & 0.05 \\
L-Lysine & 0.20 \\
Methionine & 0.15 \\
\hline \multicolumn{1}{c}{ Total } & 100.00 \\
\hline Chemical analysis (\%) & \\
Dry matter (DM) & 90.93 \\
Crude protein (CP) & 17.40 \\
Crude fat & 3.75 \\
Crude fiber & 3.22 \\
Crude ash & 11.64 \\
Ca & 3.47 \\
Available P & 0.55 \\
ME (kcal/kg) & 2,808 \\
Lys & 0.82 \\
Met & 0.41 \\
\hline & \\
\hline &
\end{tabular}

* Provided the following nutrients per kg of diet: vitamin-A, 12,000 IU; vit- $\mathrm{D}_{3}, 1,000 \mathrm{IU}$; vit-E, $20 \mathrm{IU}$; vit- $\mathrm{K}_{3}, 4 \mathrm{mg}$; vit $\mathrm{B}_{1}, 1.5 \mathrm{mg}$; vit $\mathrm{B}_{2}, 5 \mathrm{mg}$; vit $\mathrm{B}_{6}, 4 \mathrm{mg}$; vit $\mathrm{B}_{12}, 1 \mathrm{mg}$; pantothenic acid, 10 $\mathrm{mg}$; niacin, $30 \mathrm{mg}$; biotin, $0.05 \mathrm{mg}$; folic acid, $5 \mathrm{mg}$; $\mathrm{Cu}, 12 \mathrm{mg}$; Fe, 240 mg, Zn, 40 mg; Mn, 48 mg; Co, 0.3 mg; Se, $1.2 \mathrm{mg}$.

\section{Performance Parameters}

The performance parameter such as hen day egg production (HDEP) and average egg weight was recorded daily. Data were calculated and expressed as weekly basis from $21^{\text {st }}$ to $30^{\text {th }}$ week of age. Feed consumption was measured each week by the recorded amounts of supplied feed and residual feed. FCR was determined by the ratio between egg weight and feed consumption. Individual body weights were recorded every 2 weeks starting at $20^{\text {th }}$ week. 


\section{Egg Quality Analysis}

A total of 120 eggs, 20 eggs from each replication, were randomly collected from different treatment groups at $30^{\text {th }}$ week of age. All eggs were individually weighed and dirty eggs from each replication were counted daily and recorded weekly basis. Width and length $(\mathrm{cm})$ of each egg were measured using a manual calipers and shape index was calculated as percent ratio between egg width and egg length, using the equation reported by Khalafalla and Bessei (1995). Shell thickness meter was used to determine the shell thickness $(\mathrm{mm})$ of egg. Shell strength $\left(\mathrm{kg} / \mathrm{cm}^{2}\right)$ of un-cracked egg was measured using the equation suggested by Arad and Marder (1982). The height of albumen and yolk were measured using a standard tripod micrometer and diameter of albumen and yolk were measured by slide calipers. Haugh unit were estimated according to the equation proposed by Haugh (Stadelman, 1995) and yolk color of eggs were evaluated by comparison with the Rochefan (DSM, 2005-HMB, 51548, Switzerland).

Statistical analysis and $t$-test of all experimental data was performed using SPSS statistical software package (version 12.0 for Windows, SPSS, Inc., Chicago, IL).

\section{RESULTS AND DISCUSSION}

Laying performance and the results of other related parameters were shown in Table 2. The difference in HDEP (\%) between rearing systems was not statistically significant in the present study. In the whole experimental period, birds raised at cage performed better than those raised at barn. The result is somewhat different from the findings of Anderson and Adams (1994) and Muthusamy and Viswanathan (1998) who found no significant differences in HDEP between barn and cages. However, some other studies (Abrahamsson et al., 1996; Tauson et al., 1999) have reported that egg production of laying hens was slightly higher in cage than those housed in alternative systems such as aviaries, barn, or free range. Moreover, Bangcong and Cagmat (1990) and Mostert et al. (1995) reported the significantly higher egg production in cages than on littered floor. In Fig. 1, change in weekly average egg production was compared between two systems. Lower HDEP by barn hens was only remarkable up to $25^{\text {th }}$
Table 2. Performance characteristics of egg laying pullets in barn or cage systems

\begin{tabular}{lrrl}
\hline \hline \multicolumn{1}{c}{ Parameter } & $\begin{array}{c}\text { Barn } \\
(\text { Mean } \pm \text { SEM) }\end{array}$ & $\begin{array}{c}\text { Cage } \\
(\text { Mean } \pm \text { SEM) }\end{array}$ & $\begin{array}{c}P \\
\text { value }\end{array}$ \\
\hline Hen day egg production (\%) & $78.63 \pm 3.15$ & $81.95 \pm 1.00$ & $\mathrm{NS}$ \\
Body weight (g) & $1,534.79 \pm 43.18$ & $1,498.89 \pm 7.03$ & $\mathrm{NS}$ \\
Feed consumption (g/bird/d) & $116.51 \pm 0.69$ & $105.77 \pm 0.76$ & $0.0015^{* *}$ \\
Egg weight (g/egg) & $54.42 \pm 0.29$ & $52.81 \pm 0.15$ & $0.0467^{*}$ \\
Egg mass output (g/d) & $43.87 \pm 2.51$ & $44.34 \pm 1.06$ & $\mathrm{NS}$ \\
FCR (g of feed : g of egg) & $2.86 \pm 0.31$ & $2.49 \pm 0.25$ & $\mathrm{NS}$ \\
Livability (\%) & $95.83 \pm 4.17$ & $100.00 \pm 0.00$ & $\mathrm{NS}$ \\
\hline
\end{tabular}

NS; not significant, ${ }^{* *} ; P<0.01,{ }^{*} ; P<0.05$, SEM; standard error of mean.

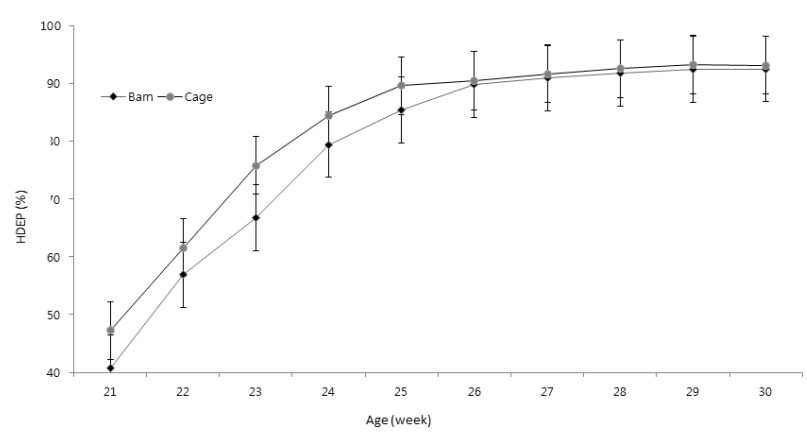

Fig. 1. Effect of barn or cage systems on weekly HDEP of egg laying pullets.

week of age, which was initial 5 weeks. This result suggested that the free movement or other conditions at barn might retard early egg production. The reason could be relatively heavier body weight of barn pullet (Álvarez and Hocking, 2012), or stress caused by sudden exposure to free movement environment (Cid et al., 2011).

Housing system did not significantly affect the body weight of pullets during the early stage of laying period. Almost similar average body weight was observed in both systems although the body weight of barn pullet was numerically heavier. The finding of Bangcong and Cagmat (1990) was similar with this result, that they found non-significant difference in body weight among systems.

Average weight of barn eggs was significantly $(P<0.05)$ 
heavier than that of cage eggs. Several observations (Singh et al., 2009; Lewko and Gornowicz, 2011) also agreed with this finding that reported heavier barn eggs than cage eggs. However, Bangcong and Cagmat (1990) found heavier egg weight in cages than that kept on barn. The average egg weight has been evidently associated with number of eggs as far as the amount of feed consumed are within normal range.

As shown in Table 2, data for daily feed consumption was significantly $(P<0.01)$ higher in barn layers $(116.51 \mathrm{~g})$ than in cage layers $(105.77 \mathrm{~g})$. Fig. 2 represent the amount of feed consumed by the birds at each week. Barn system can be characterized with more space for pullets that allows free movement. It is believed that, an opportunity of free movement requires more energy expenditure that need to be supported by increasing feed intake. This was in the line with the findings of Preisinger (2000), who reported that birds in non-caged system tended to eat more feed compared with those in cage system to provide energy for heat production. However, Singh et al. (2009) found no variation in feed consumption between barn and cage birds in the early life (up to $30^{\text {th }}$ week) of production. There was no significant difference in FCR between the two housing systems. However, numerically poor FCR was shown in the barn layers probably due to more feed consumption. This is in accordance with the findings of Muthusamy and Viswanathan (1998) who found non-significant difference of FCR between barn and cage birds. However, Mostert et al. (1995) reported significantly higher FCR and daily egg mass in cage than those in barn.

Daily egg mass output was not significantly different between two housing systems in this study as shown in Table 2. Almost similar egg mass was observed from both systems since HDEP was lower in barn bird but of which egg weight

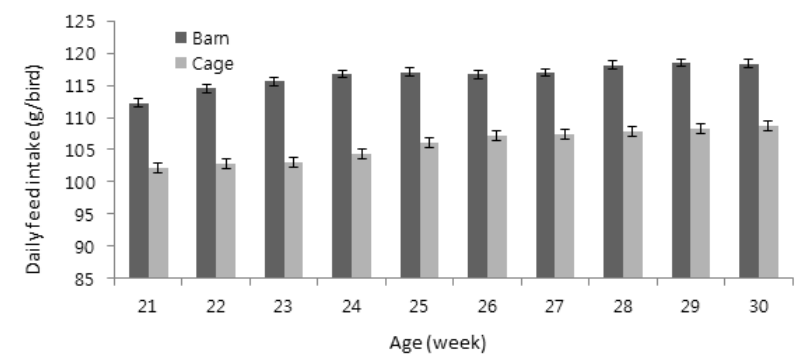

Fig. 2. Effect of barn or cage systems on daily feed intake of egg laying pullets at different weeks was heavier. Although the impact of higher feed consumption by barn layers was alleviated by heavier egg mass, practically the alleviation was not enough to exert the same egg mass output. Therefore, the barn birds exerted numerically less egg mass output and poorer FCR compared to those of cage birds.

Dead bird was reported only in the barn layers as shown in Table 2. Since there was a variation among replicates of barn system, the data did not show a statistical significance. It suggested that the mortality could be affected by many different management methods of any housing systems. Therefore, in this study, it was difficult to mention that the barn system was inferior to the cage system on livability of laying pullets. Tauson et al. (1999) found overall mortality of hybrid layers was slightly higher in floor pens than in cages, which is similar to the result of this study.

In this study, shape index, shell thickness, breaking strength and cleanliness of egg were evaluated as the external egg quality parameters. Only shell thickness and dirty egg differed significantly $(P<0.01)$ between two housing systems, but other quality parameters were similar between two housing systems (Table 3). Present study and some other observations (Lewko and Gornowicz, 2011; Dukic-Stojcic et al., 2009) found no significant difference on shape index between barn and cage eggs. However, Mohan et al. (1991) found significantly higher shape index in barn than in cage.

Egg shell thickness was influenced significantly $(P<0.01)$ by the housing system (Fig. 3), which was higher (0.404 $\mathrm{mm})$ in barn than in cage $(0.377 \mathrm{~mm})$. A number of other

Table 3. External egg quality characteristics of eggs from barn or cage systems

\begin{tabular}{lccc}
\hline \hline \multicolumn{1}{c}{ Parameter } & $\begin{array}{c}\text { Barn } \\
(\text { Mean } \pm \text { SEM) }\end{array}$ & $\begin{array}{c}\text { Cage } \\
(\text { Mean } \pm \text { SEM) }\end{array}$ & $\begin{array}{c}P \\
\text { value }\end{array}$ \\
\hline Shape index (\%) & $79.87 \pm 1.08$ & $79.83 \pm 0.54$ & NS \\
Shell thickness $(\mathrm{mm})$ & $0.404 \pm 0.006$ & $0.377 \pm 0.006$ & $0.0053^{* *}$ \\
Breaking strength $\left(\mathrm{kg} / \mathrm{cm}^{2}\right)$ & $2.90 \pm 0.03$ & $2.87 \pm 0.02$ & $\mathrm{NS}$ \\
Dirty egg (\%) & $2.08 \pm 0.09$ & $0.61 \pm 0.03$ & $0.0018^{* *}$ \\
Blood spot (\%) & $0.16 \pm 0.05$ & $0.23 \pm 0.09$ & $\mathrm{NS}$ \\
\hline
\end{tabular}

NS; not significant, ${ }^{* *} ; P<0.01,{ }^{*} ; P<0.05$, SEM; standard error of mean. 


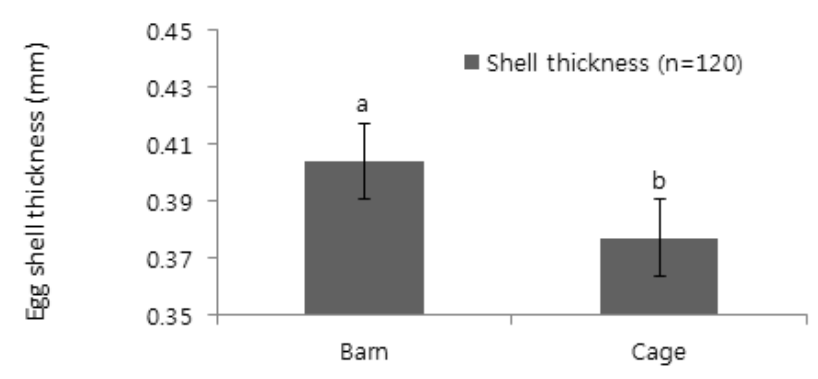

Fig. 3. Effect of barn or cage systems on egg shell thickness

studies (Hidalgo et al., 2008; Pavlovski et al., 2001; Leyendecker et al., 2001) reported that shell in barn eggs was thicker than that in cage eggs. On the other hand, Tumova and Ebeid (2003) noticed thicker shell in cage eggs compared with that in barn eggs. There was no difference in breaking strength between barn and cage eggs. This result is agreed with Sauveur (1991) who found no significant difference on breaking strength in the eggs from different housing systems.

Fig. 4 showed the percent of dirty egg between two housing systems. Significantly $(P<0.01)$ higher percentage of dirty egg was occurred in barn (2.08) than in cage (0.61). The result is also partially supported by Belyavin (1988) who found the higher incidence of dirty and soiled eggs in floor production than in cage. Higher number of dirty eggs in barn could be attributed to the longer stay of eggs in laying nest has increased the exposure with excreta. There was no difference in percentage of egg blood spot between to housing systems although the percentage was numerically higher in cage eggs than barn. Sauveur (1991) also reported no significant differences in blood spots between barn and cage systems.

There were remarkable differences $(P<0.01)$ between barn and cage eggs on internal quality of egg. Average albumen

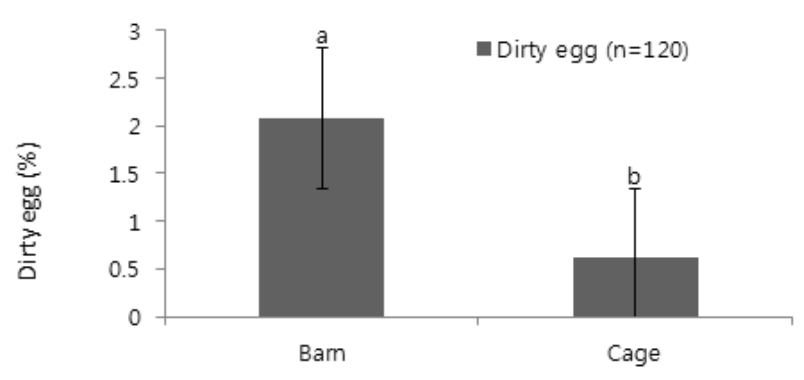

Fig. 4. Effect of barn or cage systems on dirty egg height and Haugh unit (HU) values (Fig. 5) were higher in eggs from cage than in those from barn. Singh et al. (2009) found lower albumen height in eggs from barn than cage system, which was similar to the result of the present study. It is known that HU value directly depends on the albumen height and egg weight (Stadelman, 1995). Higher HU value of cage eggs would be attributed to higher albumen height and lower egg weight. Pavlovski et al. (1994) found significantly higher HU in cage eggs than in barn eggs, which also similar to the present study. However, Sauveur (1991) and Mohan et al. (1991) found no significant difference in albumen quality due to housing systems. Result of present study (Fig. 6) showed that yolk color score was significantly $(P<0.01)$ higher in cage eggs (5.61) than in barn eggs (4.83). It has been well known that, yolk color is primarily affected by the characteristics of the diet (Lesson and Summers, 1991). However, there were also other (Singh et al., 2009; Lewko and Gornowicz, 2011) reports that more yellowish yolk color in eggs from barn. In addition, housing system did not affect any significant difference on yolk index (Table 4). Almost same values between cage and barn eggs (0.466 and 0.468) of yolk index were found in the present study. However, Mohan et al. (1991) found significantly higher yolk index

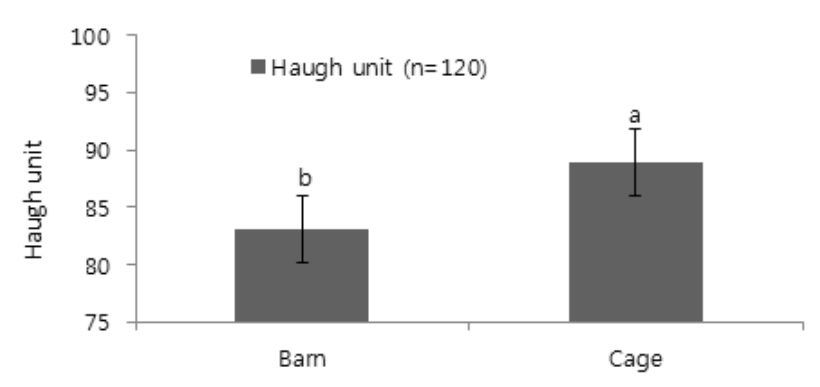

Fig. 5. Effect of barn or cage systems on Haugh unit of egg

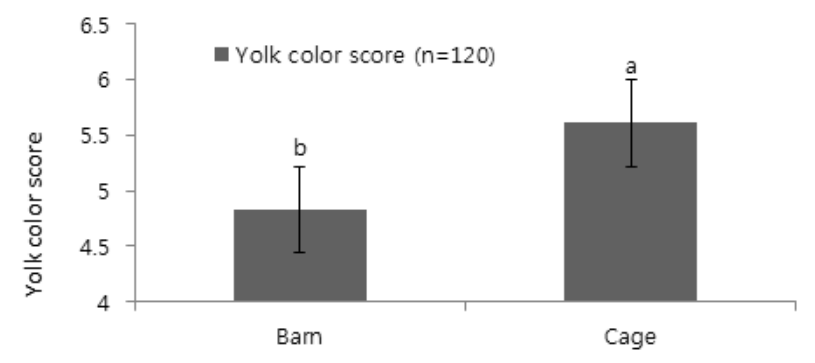

Fig. 6. Effect of barn or cage systems on yolk color score. Where, higher score represents more yellowish yolk 
Table 4. Internal egg quality characteristics of eggs from barn or cage systems

\begin{tabular}{lccc}
\hline \hline \multicolumn{1}{c}{ Parameter } & $\begin{array}{c}\text { Barn } \\
(\text { Mean } \pm \text { SEM) }\end{array}$ & $\begin{array}{c}\text { Cage } \\
(\text { Mean } \pm \text { EM) }\end{array}$ & $\begin{array}{c}P \\
\text { value }\end{array}$ \\
\hline Albumen height $(\mathrm{mm})$ & $6.87 \pm 0.68$ & $8.16 \pm 0.37$ & $0.0072^{* *}$ \\
Haugh unit & $83.11 \pm 1.04$ & $88.97 \pm 1.13$ & $0.0388^{*}$ \\
Yolk index & $0.466 \pm 0.005$ & $0.468 \pm 0.005$ & $\mathrm{NS}$ \\
Yolk color score & $4.83 \pm 0.25$ & $5.61 \pm 0.23$ & $0.0087^{* *}$ \\
\hline
\end{tabular}

NS; not significant, ${ }^{* *} ; P<0.01, \stackrel{*}{;} ; P<0.05$, SEM; standard error of mean.

in barn eggs than in cage eggs whereas Pavlovski et al. (1994) found no difference in yolk index between barn and cage.

\section{CONCLUSION}

This study showed that the egg production performance of egg laying pullet was not significantly influenced by the housing systems, except the feed consumption and egg weight. On the other hand, egg quality parameters such as shell thickness, HU, yolk color were influenced significantly by the housing systems. Therefore, result of the study implied that the barn system can be successfully used since the sacrifice on performance was relatively minimal considering the advantage of welfare bestowed egg production. This study also suggested that management of barn should be accompanied to reduce dirty egg.

\section{REFERENCES}

Abrahamsson P, Tauson R, Elwinger K 1996 Effect on production, health and egg quality of varying proportions of wheat and barley in diets for two hybrids of laying hens kept in different housing systems. Acta Agric Scand $46: 254-260$.

Al-Awadi AA, Husseini MD, Diab MF, Al-Nasser AY 1995 Productive performance of laying hens housed in minimal shade floor pens and laying cages under ambient condition in hot arid regions. Livest Prod Sci 41:263-269.

Álvarez R, Hocking PM 2012 Changes in ovarian function and egg production in commercial broiler breeders through 40 weeks of lay. Br Poult Sci 53:386-93.

Anderson KE, Adams AW 1994 Effect of cage versus floor rearing environments and cage floor mesh size on bone strength, fearfulness and production of Single Comb White Leghorn hens. Poultry Sci 73:1233-1240.

Arad Z, Marder J 1982 Differences in egg shell quality among the Sinai Bedouin fowl, the commercial White Leghorn and their crossbred. Br Poult Sci 23:107-112.

Bangcong RS, Cagmat DC 1990 Production performance of Hy-Line brown layers raised in cage and floor at Central Mindanao University. Poultry Project CUM j Sci 7:17.

Belyavin CG 1988 Egg quality as influenced by production systems. Worlds Poult Sci J 44:65-67.

Cid MP, Kirkwood CA, Arce A, Salvatierra NA 2011 Neonatal stimulation improves egg production in laying hens. Rev Vet 22(1):8-12.

Dukic-Stojcic M, Peric L, Bjedov S, Milosevic N 2009 The quality of Table eggs produced in different housing systems. Biotech Anim Husbandry. 25:1103-1108.

Fraser AC, Bain MM 1994 A comparison of eggshell structure from birds housed in conventional battery cages and in a modified free-range system. Pages 151-152 in Proc. $9^{\text {th }}$ European Poult. Conf. World's Poultry Science Association, United Kingdom Branch, Glasgow, UK.

Groot Koerkamp PWG 1998 Ammonia emission from aviary housing systems laying hens. $\mathrm{PhD}$ Thesis. Wageningen University. Wageningen, the Netherlands.

Hidalgo A, Rossi M, Clerici F, Ratti S 2008 A market study on the quality characteristics of eggs from different housing systems. Food Chem 106:1031-1038.

Khalafalla MK, Bessei W 1995 Reliability of quasi-static compression as an indicator of eggshell quality. In Proceeding of the VI European Symposium of the Quality of Egg and Egg Products, (25-29 September) Zaragoza, Spain: $67-71$.

Lesson S, Summers JD 1991 Commercial Poultry Nutrition. University Books. Guelph. Ontario. Canada.

Lewko L, Gornowicz E 2011 Effect of housing system on egg quality in laying hens. Am Anim Sci 11(4):607-616.

Leyendecker M, Hamann H, Hartung J, Kamphues J, Ring C, Gluunder G 2001 Analysis of genotype-environment inter- 
actions between layer lines and hen housing systems for performance traits, egg quality and bone breaking strength. 2nd communication: Egg quality traits. Zü chtungskunde 73:308-323.

Mohan B, Mani V, Nagarazan S 1991 Effect of different housing systems on the physical qualities of commercial chicken eggs. Ind J Poult Sci 26:130-131.

Mostert BE, Bowes FH, Walt JC 1995 Influence of different housing systems on the performance of hens of four laying strains. South Afri J Anim Sci 25:80-86.

Muthusamy P, Viswanathan K 1998 Effect of rearing systems on performance of commercial layers. Ind J Poult Sci 33 :264-267.

Pavlovski Z, Hopic S, Lukic M 2001 Housing system for layers and egg quality. Biotech Anim Husbandry 17:197-201.

Pavlovski Z, Hopic S, Nracar S, Masic B 1994 The effects of housing systems on internal egg quality traits in small stocks of layers. Biotech Stocarstvu 10:37-43. In Poult Abst (1997), 23:607.

Preisinger R 2000 Lohmann Tradition, Praxiserfahrung und Entwicklungsperspektiven. Lohmann Inform 3:13-16.

Sauveur B 1991 Effect of method of rearing of fowls on egg characters. Prod Anim 4:123-130.

Shaver 579 Layer Management Guide 2009 www.isapoultry.com /en/Products/Shaver.aspx.

Singh R, Cheng KM, Silversides FG 2009 Production perfor- mance and egg quality of four strains of laying hens kept in conventional cages and floor pens. Poultry Sci 88:256264.

Stadelman WJ 1995 Quality identification of shell eggs. In WJ Stadelman \& OJ Cotterill (Eds.), Egg Science and Technology (pp. 39-66). New York: Food Products Press, The Haworth Press, Inc.

Suto Z, Horn P, Ujvari J 1997 The effect of different housing systems on production and egg quality traits of brown and Leghorn type layers. Acta Agraria Kaposvariensis 1:2935.

Tauson R, Wahlstrom A, Abrahamsson P 1999 Effect of two floor housing systems and cages on health, production, and fear response in layers. J Appl Poult Res 8:152-159.

Taylor AA, Hurnik JF 1996 The long-term productivity of hens housed in battery cages and aviary. Poultry Sci 75:47-51.

Tumova E, Ebeid T 2003 Effect of housing system on performance and egg quality characteristics in laying hens. Scientia Agriculturae Bohemica 34:73-80.

Vits A, Weizenburger D, Hamann H, Distl O 2005 Influence of different small group systems on production traits, egg quality and bone breaking strength of laying hens. First communication: Production traits and egg quality. Zuchtungskunde 77:303-323.

(접수: 2013. 3. 18, 수정: 2013. 3. 25, 채택: 2013. 3. 25) 